\title{
PENGEMBANGAN LEMBAR KERJA SISWA P4 INTERAKTIF MATA PELAJARAN IPA TERPADU UNTUK SISWA SMP BERBASIS BUDAYA LOKAL MASYARAKAT NGADA FLORES
}

\author{
Ngurah Mahendra Dinatha \\ STKIP Citra Bakti, Nusa Tenggara Timur, Indonesia \\ Email: ngurahm87@gmail.com \\ Putu Arimbawa S. \\ STKIP Citra Bakti, Nusa Tenggara Timur, Indonesia \\ Email: sarnoxarimbawa@gmail.com
}

\begin{abstract}
Abstrak
Tujuan dari penelitian ini adalah 1) menghasilkan lembar kerja siswa (LKS) P4 interaktif berbasis budaya lokal dalam pembelajaran IPA SMP kelas IX di daerah Ngada, dan 2) mendeskripsikan kualitas hasil uji coba produk pengembangan lembar kerja siswa (LKS) P4 interaktif budaya lokal dalam pembelajaran IPA SMP kelas IX di daerah Ngada. LKS P4 interaktif ini dikembangkan dengan model ADDIE (analyze, design, development, implementation, dan evaluation). Penelitian ini dilakukan di Kabupaten Ngada Provinsi Nusa Tenggara Timur. Data yang telah dikumpulkan dalam penelitian ini dianalisis secara deskriptif kualitatif untuk menjelaskan efektivitas LKS P4 interaktif yang akan dikembangkan. Hasil penelitian menunjukkan bahwa (1) LKS yang dikembangkan adalah LKS P4 interaktif yang mencakup materi IPA terpadu kelas XI di tingkat SMP, (2) terdapat beberapa konten budaya daerah yang diintegrasikan ke dalam LKS P4 interaktif, antara lain cara membuat makanan olahan secara tradisional, dan (3) LKS P4 interakif yang dikembangkan terintegrasi budaya lokal Masyarakat Ngada ada dalam kategori sangat baik berdasarkan penilaian ahli dan uji coba kepada siswa SMP.
\end{abstract}

Kata kunci: LKS P4 interaktif, budaya lokal Ngada.

\begin{abstract}
This present study aims to 1) develop local culture based P4 students' worksheet for ninth graders in Ngada regency on natural science course, and 2) describe the quality of the product after being tried out. This P4 worksheet is developed by adapting the ADDIE model (analyse, design, development, implementation, and evaluation). Further, the study was conducted in Ngada regency, East Nusa Tenggara Province. In addition, the gathered data will analysed descriptive qualitatively focusing on the effectiveness of the developed P4 students' worksheet. This study results in (1) the developed interactive P4 students' worksheet encompasses all natural science materials for ninth graders, (2) There are parts from local culture which are integrated into the worksheet, one to mention is how to make traditional food, and (3) experts and ninth grade students consider the developed worksheet is a success with a good quality product.
\end{abstract}

Keywords: Interactive P4 worksheet, Ngadanese Local Culture

\section{Pendahuluan}

Ilmu Pengetahuan Alam (IPA) merupakan ilmu yang mempelajari gejala-gejala melalui serangkaian proses yang dikenal dengan proses ilmiah. Pembelajaran IPA menekankan pada pemberian pengalaman langsung yang bertujuan untuk mengembangkan kopetensi agar dapat menjelajahi dan memahami alam sekitar secara alamiah. Selain itu pelajaran IPA juga dapat membentuk karakter peserta didik ke arah yang lebih baik (Dinatha, 2018).

Melihat pentingnya penguasaaan sains dalam peningkatan mutu sumber daya manusia dan manfaatnya dalam kehidupan keseharian, maka sudah sewajarnya pelajaran IPA diperkenalakan sejak dini. Kenyataannya keluhan dan kekecewaan terhadap hasil yang dicapai siswa dalam pelajaran IPA hingga kini sering diungkapkan. Dinatha (2017) menyatakan bahwa tingkat kesulitan belajar siswa pada pelajaran IPA dikatakan dalam kategori sedang. Penelitian dibeberapa negara menunjukkan bahwa sains, terutama pelajaran IPA menjadi salah satu mata pelajaran yang kurang disukai. Salah satu penyebab dari keadaan ini adalah pelajaran IPA banyak mempelajari hal-hal yang abstrak. Menurut Gabel, keabstrakan menjadikan pelajaran ini sebagai pelajaran yang kompleks sehingga sulit untuk dipelajari. Selain itu, Coll \& Taylor menyebutkan banyak penelitian yang menunjukkan bahwa terjadi kesulitan memahami konsep-konsep IPA karena ketidakmampuan menghubungkan dunia makroskopis dan mikroskopis. 
Keadaaan ini akan diperparah dengan adanya isu tentang berlakunya full day school yang akan diterapkan di Indonesia. Dimana siswa diwajibkan untuk belajar melewati batas waktu normal belajar di sekolah. Artinya siswa lebih banyak menghabiskan waktu di sekolah dengan guru dan teman-temanya. Pengertian full day school adalah sekolah sepanjang hari atau proses belajar mengajar yang diberlakukan dari pagi hari sampai sore hari, dengan durasi istirahat setiap dua jam sekali. Hal ini tentu akan mempengaruhi bagaimana cara guru untuk mengajar dan mengelola kelas dengan baik agar materi yang diajarkan dapat dimengerti oleh siswa.

Untuk mengelola kelas agar tetap terkendali maka guru menggunakan LKS yang saat ini sudah banyak digunakan di sekolah-sekolah. Guru banyak terbantu dengan LKS sebagai salah satu pegangan guru dan siswa untuk mengaktifkan siswa di kelas. Namun LKS yang ada selama ini belum mencakup banyak aktivitas yang melibatkan siswa dan kurangnya kegiatan yang menantang bagi siswa (Salirawati, 2007). Selaian itu LKS yang merupakan hasil dari suatu penerbit yang mungkin tidak sesuai dengan lingkungan di mana siswa tersebut belajar. Kondisi ini tentunya dapat mempersulit siswa dalam memahami materi yang seharusnya mereka kuasai. Dalam proses menyusun dan mengembangkan kegiatan pembelajaran harus memperhatikan prinsip-prinsip penyusunan dan pengembangan sesuai dengan kondisi di satuan pendidikan baik kemampuan awal peserta didik, minat, motivasi belajar, bakat, potensi, kemampuan sosial, emosi, gaya belajar, kebutuhan khusus, kecepatan belajar, latar belakang budaya, norma, nilai, dan/atau lingkungan peserta didik (Kemendikbud, 2013).

Penyelidikan, penyusunan dan penyajian gagasan-gagasan dalam pembelajaran IPA dapat dilakukan dalam beberapa model pembelajaran. Salah satu model pembelajaran yang sangat berkaitan dengan pembelajaran IPA adalah Pembelajaran Berbasis Proyek (PBP). Menurut NYC Department of Education tahun 2009, pembelajaran berbasis proyek merupakan pembelajaran yang mampu memperkuat siswa dalam mencapai pengetahuan melalui pemahaman mereka sendiri serta mampu menunjukkan pemahaman mereka melalui berbagai cara. Lebih lanjut disampaikan bahwa pembelajaran berbasis proyek sangat cocok diterapkan untuk siswa SMP. Hal ini dikarenakan siswa SMP sudah mulai memiliki pemikirin yang kritis terhadap suatu hal atau peristiwa yang berkaitan dengan fenomena alam. PBP memfasilitasi siswa untuk melakukan penelitian, investigasi, dan presentasi secara aktif dan autentik. Pernyataan ini didukung dengan "Project-based learning refers to students designing, planning, and carrying out an extended project that produces a publicly-exhibited output such as a product, publication, or presentation" (Patton, 2012). Pernyataan ini mendukung siswa secara mandiri belajar menemukan pemahamannya sendiri yang sesuai dengan paham konstruktivisme.

Penggunaan LKS P4 (Perencanaan, Pelaksanaan, Peninjauan Kembali, dan Perbaikan) interaktif berbasis budaya lokal menjadi salah satu alternatif untuk menerapkan sistem balajar aktif. LKS P4 interaktif mengutamakan siswa untuk mengatur waktu pembuatan proyek dalam pembelajarn berbasis proyek (PBP). Dengan menggunakan LKS P4 interaktif berbasis budaya lokal, siswa dibimbing untuk memprediksikan, selanjutnya melakukan observasi dan akhirnya siswa akan menjelaskan benar atau salah prediksi awal yang mereka ambil atau buat. Pembelajaran yang bermakna dan sesuai dengan kebutuhan belajar siswa adalah pembelajaran yang melibatkan seluruh sensoris peserta didik. Keterlibatan ini tentunya harus mendapat dukungan strategi penyampaian materi dengan yang memaksimalkan fungsi panca indera (Meyer, 2007). Maksimalnya fungsi tersebut dapat dilakukan dengan menggunakan media pembelajaran yang mengandung teks, video dan animasi (multimedia). Selain digunakan sebagai media pembelajaran, perkembangan teknologi informasi dan komunikasi juga dimanfaatkan pada aspek penilaian, yaitu untuk menilai sikap ilmiah peserta didik melalui media sosial (Dinatha, 2017). Selain itu pembelajaran yang dilakukan harus melibatan penuh siswa, menggunakan sumber belajar yang ada dilingkungan sekitarnya, termasuk budaya lokal, serta mempunyai potensi tinggi untuk dapat dimanfaatkan siswa dalam kehidupan nyata (Alexon, 2010).

Dalam pembelajaran berbasis budaya, siswa tidak hanya mempelajari isi materi pelajaran saja, tetapi mengaitkan sisi budaya lokal setempat dengan materi pelajaran yang diajarkan. Hal ini tentu akan membuat siswa lebih aktif dan termotivasi untuk mempelajari materi yang diajarkan oleh guru, sebab siswa bukan sekedar meniru atau menerima informasi saja tetapi siswa menciptakan makna pemahaman dan arti informasi yang diperolehnya.

Selain itu penggunaan LKS interaktif berbasis budaya lokal dapat digunakan untuk menggali ide siswa dan juga menyediakan informasi bagi guru untuk mengetahui cara berfikir siswa, memicu terjadinya kegiatan diskusi, memotivasi siswa untuk mengeksplor pengetahuan konsepsi siswa, memicu siswa untuk melakukan investigasi. Sehingga siswa akan lebih aktif dalam proses pembelajaran di dalam kelas.

Untuk itu perlu dilakukan upaya pengembangan LKS interkatif yang mengutamakan unsur kearifan lokal khususnya budaya lokal masyarakat Ngada yang memiliki ragam budaya yang sangat cocok dimasukkan dalam pembelajaran di Sekolah Menengah Pertama. Untuk itulah perlu dilakukan pengkajian mengenai kearifan lokal masyarakat Ngada dalam implementasinya untuk menghasilkan LKS P4 interkatif yang relevan digunakan.

\section{Metode}

LKS P4 interaktif ini dikembangkan dengan model ADDIE (analyze, design, development, implementation, dan evaluation). Secara visual, kelima tahapan model ADDIE dapat dilihat pada Gambar 1. 


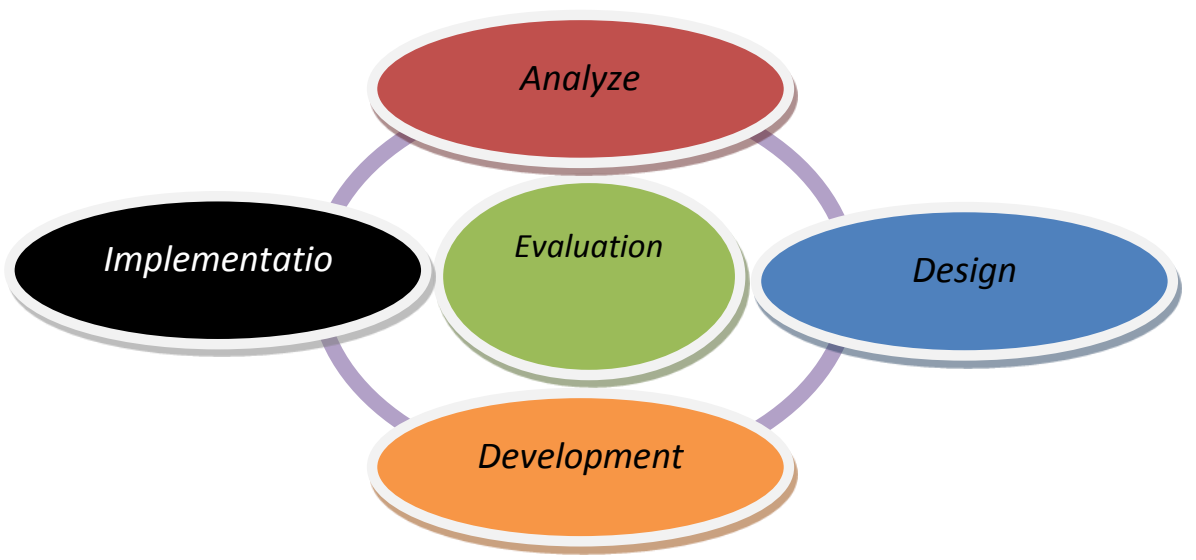

Gambar 1. Model ADDIE (McGriff, 2000)

Pada tahap analisis (analyze), meliputi kegiatan analisis kebutuhan belajar SMP kelas IX yang dapat diintegrasikan dengan unsur kearifan lokal Masyarakat Ngada. Pada tahapan perancangan (design), unsur-unsur kearifal lokal yang relevan diintegrasikan dalam LKS P4 interaktif untuk siswa SMP kelas IX. Pada tahapan pengembangan (development), dilakukan dengan membuat LKS P4 inetraktif dengan menggunakan software macro media flash. Pada tahapan implementasi (implementation), kegiatan dilakukan uji coba terbatas LKS P4 interaktif berbasis kearifal lokal Masyarakat Ngada kepada guru/dosen dan siswa. Selanjutnya, pada tahapan evaluasi (evaluation), dilakukan revisi LKS P4 interaktif yang dihasilkan berdasarkan hasil uji coba.

Penelitian ini dilakukan di Kabupaten Ngada Provinsi Nusa Tenggara Timur. Subjek dalam penelitian ini adalah kurikulum 2013 kelas IX serta guru dan siswa SMP kelas IX di Kecamatan Bajawa Kabupaten Ngada. Pengambilan subyek siswa dan guru dilakukan dengan teknik cluster yaitu dengan memperhatikan karakteristik sekolah dan wilayah Kecamatan Bajawa Kabupaten Ngada. Sedangkan objek yang diteliti adalah LKS P4 interaktif berbasis budaya lokal Masyarakat Ngada yang relevan diintegrasikan dalam pembelajaran di SMP.

Data yang telah dikumpulkan dalam penelitian ini dianalisis secara deskriptif kualitatif sebagai berikut. (1) Data mengenai kualitas LKS P4 interaktif hasil review ahli dianalisis secara deskriptif untuk mengolah data hasil review ahli isi mata pelajaran, ahli desain pembelajaran, ahli media pembelajaran dan uji coba siswa. Teknik analisis data ini dilakukan dengan mengelompokan informasi dari data kualitatif yang berupa masukan, tanggapan, kritik, dan saran perbaikan yang terdapat pada angket. Hasil analisis ini kemudian digunakan untuk merevisi produk yang dikembangkan. (2) Data mengenai kualitas LKS P4 interaktif hasil uji coba produk dianalisis melalui konversi skor yang didapat dari lembar kuisoner. Pengubahan hasil penilaian dari guru/dosen dan siswa dari bentuk kualitatif ke bentuk kuantitatif skala 5.

\section{Hasil dan Pembahasan}

Penelitian awal yang telah dilakukan adalah menganalisis unsur budaya lokal yang sesuai dengan materi pelajaran IPA terpadu kelas IX. Adapun materi yang dimuat dalam LKS P4 interaktif adalah sebagai berikut 1) kemagnetan dan pemanfaatan dalam produk teknologi; 2) pewarisan sifat pada mahluk hidup; 3) bioteknologi pangan; 4) teknologi ramah lingkungan; 5) tanah dan keberlangsungan kehidupan. Sedangkan unsur budaya yang masuk dalam materi pelajaran IPA terpadu adalah moke dan sui wu. Pada tahap awal penelitian ini telah dihasilkan LKS P4 interaktif berupa buku manual dan juga dalam bentuk multimedia LKS P4 interaktif dalam program flash.

Penilaian ini melibatkan dua orang dosen ahli dan satu orang guru SMP. Hasil penilaian LKS P4 interaktif berbasis budaya Ngada ada pada kategori sangat baik. Data skor rata-rata para ahli dan skor total ratarata dapat dilihat pada grafik di bawah ini 


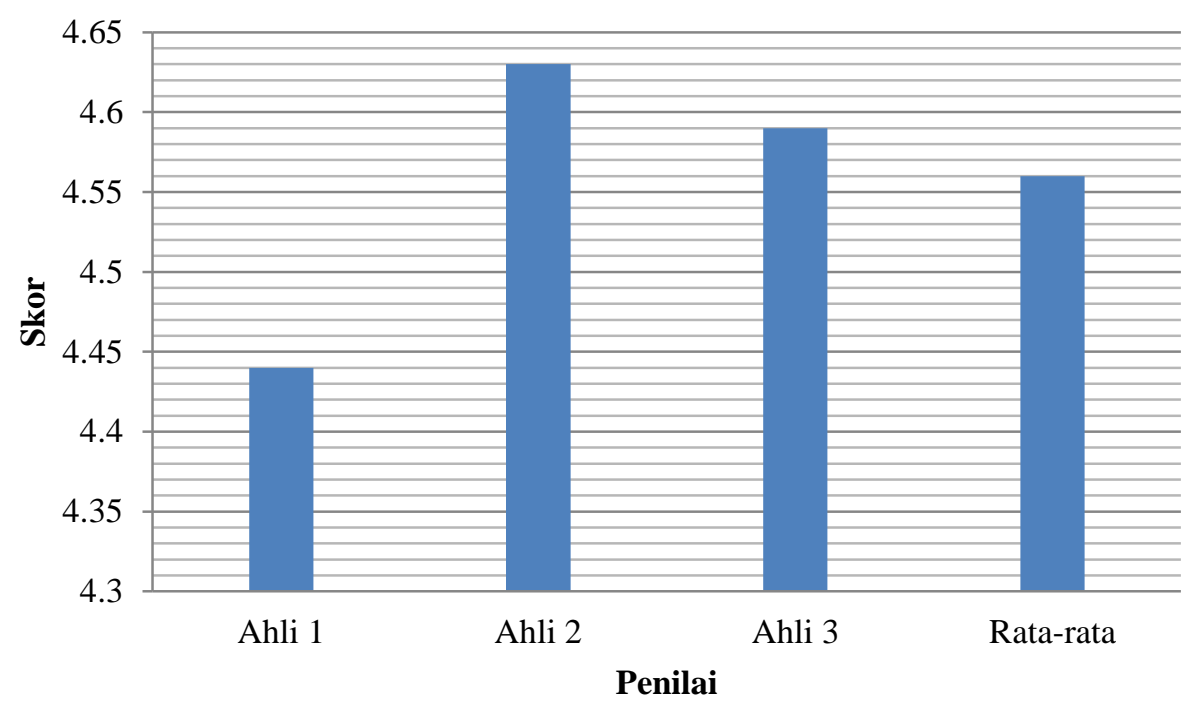

Gambar 3. Grafik Skor Rata-rata Penilaian LKS P4 oleh para Ahli

Pada grafik tersebut terlihat bahwa penilaian dari ahli 1 mendapatkan nilai yang paling rendah dari 2 orang ahli lainnya, tetapi masih berada pada kategori sangat baik yaitu dengan skor 4,44 begitu juga dengan penilaian yang dilakukan ahli 2 dan 3 dengan skor masing-masing 4,63 dan 4,59 dengan kategori sangat baik. Sehingga skor rata-rata yang diperoleh dari ketiga para ahli yaitu 4,56 dengan kategori sangat baik.

Penilaian oleh siswa melibatkan sebanyak 15 siswa dari SMPN 2 Bajawa Kabupaten Ngada, NTT. Penilaian tersebut menghasilkan LKS P4 interaktif dengan kategori sangat baik. Data skor pernyataan dan skor total rata-rata dapat dilihat pada grafik di bawah ini.

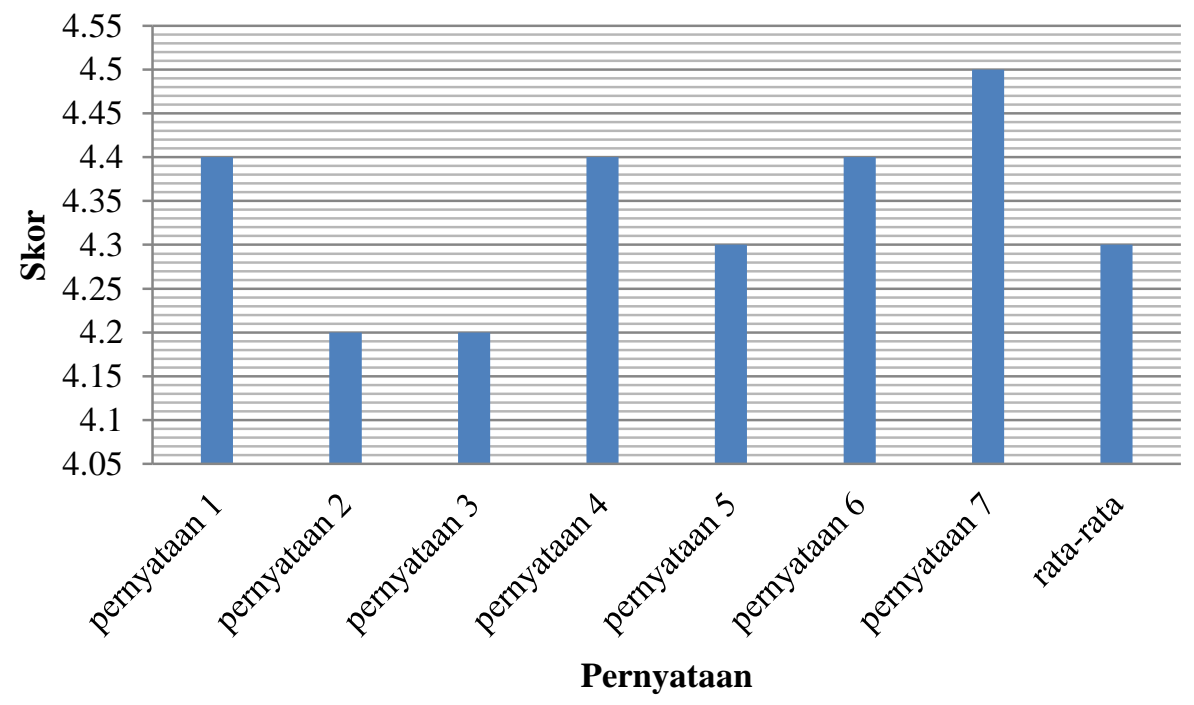

Gambar 4. Grafik Skor Penilaian Siswa terhadap LKS P4 yang Dikembangkan

Pada grafik tersebut terlihat bahwa dari ketujuh pernyataan yang diberikan mendapatkan skor rata-rata sebesar 4,3 yaitu dengan kategori sangat baik. Hal ini menunjukkan bahwa LKS P4 interaktif memberikan dampak positif dalam proses belajar dan sekaligus memotivasi siswa untuk belajar, khususnya dalam belajar IPA.

Materi IPA di SMP tentunya sudah mencakup materi yang abstrak dan sukar untuk dipahami, sehingga jika siswa kurang memahami materi yang dibaca atau dijelaskan oleh guru, maka akan menimbulkan dampak kebingungan dan akhirnya kehilangan motivasi untuk belajar. Disinilah pentingnya memberikan materi yang dekat dengan siswa yaitu berupa konten kearifan lokan masyarakat tempat siswa tersebut belajar. Beberapa kearifan lokal yang masuk dalam LKS P4 interaktif ini adalah moke dan sui wu. Kearifan lokal seperti moke dan sui wu masuk ke dalam materi yang mengajarkan mengenai cara pemanfaatan bioteknologi dengan metode lokal masyarakat Ngada. 
Pengembangan bahan ajar yang dilakukan selama ini baru dalam batas pengadaan bahan cetak berupa hand out dan ringkasan materi. Bahan cetak lain seperti buku, modul dan LKS masih sangat terbatas dihasilkan apalagi kalau bahan ajar berupa audio, visual, dan multimedia yang mengintegrasikan Teknologi Informasi dan Komunikasi (TIK). Pengembangan modul atau LKS konvensional hanya sekedar mengumpulkan materi yang langsung diajarkan kepada peserta didik tanpa melakukan analisis kebutuhan dan berbagai proses yang sistemik dan sistematis. Proses penyusunan seperti ini tidak dapat menjangkau kebutuhan peserta didik yang sesungguhnya sehinga materi pembelajaran yang disampaikan cenderung tidak dapat menarik minat peserta didik. Begitu pula, pembelajaran yang hanya mengandalkan handout dan ringkasan materi memang dapat memberikan ringkasan pelajaran yang bisa disampaikan dalam waktu singkat dan dapat dipahami lebih cepat. Akibatnya, peserta didik hanya dapat memahami secara sederhana aplikasi pembelajaran yang bersifat dangkal. Sedangkan, secara konseptual, teori-teori, postulat, dan rumus-rumus yang membangun pemahaman secara mendalam tidak dapat dijabarkan dengan sistematis dan berkelanjutan. Bahan ajar yang dikembangkan berdasarkan teori desain instruksional memegang peranan penting dalam menciptakan kondisi belajar yang kondusif. Paling tidak terdapat tiga alasan mengapa bahan ajar itu memiliki posisi sentral, yakni (1) sebagai representasi sajian tenaga pengajar, (2) sebagai sarana pencapaian tujuan pembelajaran, dan (3) sebagai pengoptimalan pelayanan terhadap peserta didik.

Untuk itu telah dikembangkan LKS P4 interaktif dengan mengintegrasikan unsur budaya lokal. Penelitian menunjukkan bahwa pembelajaran sains melalui budaya lokal pada kehidupan dan lingkungan. Untuk hidup dalam komunitas mereka, belajar IPA harus mengembangkan kemampuan untuk memecahkan masalah, berpikir global bertindak lokal, dan membawa ilmu pengetahuan untuk melayani hidup (Hadzigeorgiou \& Konsolas, 2001).

Hal ini didukung pula oleh temuan Nuangchalerm (2008) yang menyatakan bahwa lingkungan belajar IPA berdasarkan budaya lokal dapat melayani siswa dalam membangun pengetahuan ilmiah. Siswa dapat mengkombinasikan pengetahuan ilmiah dari budaya mereka sendiri dengan penyelidikan yang mereka lakukan. Belajar harus memiliki keseimbangan antara pengetahuan lokal dan pengetahuan ilmiah modern. Siswa dapat belajar dan memahami hal-hal penting untuk melayani kebutuhan dunia nyata mereka. Mereka dapat melestarikan lingkungan dan hidup bersama dengan alam melalui budaya lokal mereka masing-masing (Na Thalang, 1991).

Studi yang terkait bagaimana penguatan belajar IPA melalui budaya lokal. Ini memberikan cara untuk mengenalkan pembelajaran IPA dan studi budaya lokal. Guru dapat membawa suasana tersebut ke dalam kelas dengan menciptakan kurikulum pendidikan berdasarkan sekolah dan konteks budaya masyarakat setempat. Peserta didik akan membangun pengetahuan tentang dunia alam dan fisik. Budaya lokal dan IPA tidak bisa lepas dari kehidupan sehari-hari. Hal ini seiring dengan cara berkomunikasi, berlatih, dan berpikir mereka (Kawagley, dkk., 1998).

Belajar IPA dengan menggunakan media untuk menyampaikan pesan/informasi, memudahkan siswa dalam memahami materi pelajaran (Chinn \& Silver, 2002). Laksana \& Wawe (2015) menemukan bahwa media yang mengintegrasikan budaya lokal dapat meningkatkan pemahmaan konsep dan aktivitas belajar siswa SD. Media merupakan komponen sistem pembelajaran, yaitu strategi penyampaian (delivery system), sehingga merupakan bagian integral yang tidak bisa dipisahkan dalam pembelajaran. Fokus utama dari strategi penyampaian adalah pemilihan dan penggunaan media (Reigeluth dan Carr-Cheliman, 2009). Penetapan strategi penyampaian didasarkan pada hasil analisis sumber belajar (termasuk media) atau kendala-kendala pembelajaran (Degeng, 2013). Dengan demikian, pengkajian media akan memberikan variasi pilihan dalam menerapkan suatu strategi penyampaian materi pembelajaran.

Pengembangan adalah salah satu domain teknologi pembelajaran yang berfungsi sebagai proses penerjemahan spesifikasi desain ke dalam bentuk fisik. Kawasan pengembangan mencakup banyak variasi teknologi yang digunakan dalam pembelajaran yang dapat diorganisasi ke dalam empat kategori, yakni (1) teknologi cetak yang menyediakan landasan untuk kategori yang lain, (2) teknologi audio visual, (3) teknologi yang berasaskan komputer, dan (4) teknologi terpadu. Dalam kawasan pengembangan terdapat keterkaitan yang kompleks antara teknologi dan teori yang mendorong baik desain pesan maupun strategi pembelajaran. Pada dasarnya kawasan pengembangan dapat dijelaskan melalui; (1) pesan yang memberikan informasi, (2) strategi pembelajaran, dan (3) manifestasi fisik dari teknologi perangkat keras, perangkat lunak, dan bahan pembelajaran.

Dalam melakukan kegiatan pengembangan, beberapa pertimbangan penting yang perlu dipahami mencakup (1) mengidentifikasi tujuan pembelajaran (standar kompetensi), (2) melakukan analisis pembelajaran, (3) menganalisis peserta didik dan konteks, (4) menulis tujuan instruksional khusus (kompetensi dasar), (5) mengembangkan instrument asesment, (6) mengembangkan strategi pembelajaran, (7) mengembangkan dan menyeleksi materi pembelajaran, (8) mendesain dan melakukan evaluasi formatif, (9) melakukan revisi, dan (10) mendesain dan melakukan evaluasi sumatif.

LKS P4 interaktif dikembangkan sesuai dengan ketentuan yang ada, dan menurut para ahli media dan ahli konten bahan ajar ini sangat baik digunakan. Dari hasil yang diperoleh, LKS P4 interaktif mendapatkan nilai 4,56 atau masuk dalam kriteria "sangat baik". Hal ini terlihat dari kejelasan dan kelengkapan materi serta komposisi warna dan desian media yang sangat baik. Dengan bahan ajar seperti ini diharapkan kemampuan siswa 
untuk memahami konsep dalam mata pelajaran IPA menjadi lebih jelas dan menghindari dari kekeliruan serta memahami konsep yang benar. Penggunaan bahan ajar yang tepat akan memberikan dampak yang baik pada peserta didik, baik itu dari motivasi belajar dan hasil belajarnya.

Selain itu, tanggapan dari siswa mengenai LKS P4 interaktif juga sangat positif. Hal ini terlihat dari hasil angket yang diisi siswa, dimana diperoleh skor yaitu 4,30 atau berada pada kategori "sangat baik". Tanggapan positif siswa terjadi karena bahan ajar yang dibuat mudah untuk dimengerti dan mencantumkan animasi yang memberikan gambaran yang jelas dan spesifik mengenai Materi IPA tersebut

\section{Simpulan}

Kesimpulan dari penelitian ini adalah 1) Pengembangan LKS P4 Interaktif sudah mencapai tahap analisis kebutuhan dan penyusunan; 2) Terdapat beberapa konten budaya daerah yang dapat diintegrasikan ke dalam LKS P4 Interaktif; 3) Multimedia yang dikembangkan nanti adalah LKS P4 Interaktif budaya lokal masyarakat Ngada, yaitu pada mata pelajaran IPA Terpadu kelas IX. Beberapa saran yang peneliti berikan dalam laporan penelitian ini adalah 1) Perlu dilakukan analisis yang mendalam mengenai budaya lokal yang diintegrasikan dengan materi mata pelajaran IPA Terpadu yang sesuai; 2) Perlu dilakukan sosialisasi mengenai penggunaan LKS P4 Interaktif berbasis budaya lokal kepada pihak-pihak terkait seperti Dinas Pendidikan dan satuan penyelenggara pendidikan khususnya Sekolah Menengah Pertama (SMP).

\section{Daftar Pustaka}

Alexon. (2010). Pembelajaran Terpadu Berbasis Budaya. Unit FKIP UNIB Press. Bengkulu.

Chinn, C.A. \& Silver, C.E. (2002). Authentic inquiry: Introducing to the Special Section. Science Education, 86(2), 175-218

Coll, R.K. \& Taylor, T.G.N. (2000). Improving tertiary chemistry teaching: Implications of science education research for classroom practice. Chemistry in New Zealand.

Dinatha, N.M. (2017). Kesulitan Belajar Siswa dalam Mata Pelajaran IPA Terpadu. Jurnal Pendidikan Dasar Nusantara. 2 (2): 214-223

Dinatha, N.M. (2017). Pemanfaatan Media Sosial Facebook untuk Menilai Sikap Ilmiah (Afektif) Mahasiswa. Journal of Education Technology. 1(3). 211-217

Dinatha, N.M. (2018). Nilai-nilai Karakter dalam Pembelajaran IPA di Perguruan Tinggi. Jurnal Ilmiah Pendidikan Citra Bakti. 177-187

Degeng, I N. S. (2013). Ilmu pembelajaran: Klasifikasi variable untuk pengembangan teori dan penelitian. Bandung: Aras Media

Gabel, L. Dorothy. (1993). Hand Book of Research on Science Teaching and Learning. A Project of National science Teachers Association. New York. Macmillan Publishing Company.

Hadzigeorgiou, Y. and Konsolas, M. (2001). Global Problems and the Curriculum: Toward a Humanistic and Constructivist Science Education. Curriculum and Teaching. 16(2): 39-49.

Kawagley, A.O., Norris-Tull, D. and Norris-Tull, R.A. (1998). The Indigenous Worldview of Yupiaq Culture: Its Scientific Nature and Relevance to the Practice and Teaching of Science. Journal of Research in Science Teaching. 35(2): 133-144.

Kemendikbud. (2013). Penyusunan Rencana Pelaksanaan Pembelajaran. Jakarta: Kepala Badan Pengembangan Sumber Daya Manusia Pendidikan dan Kebudayaan dan Penjaminan Mutu Pendidikan.

Laksana, D.N.L., \& Wawe, F. (2015). Penggunaan Media Berbasis Budaya Lokal dalam Pembelajaran IPA untuk Meningkatkan Aktivitas Belajar dan Pemahaman Konsep IPA Siswa Sekolah Dasar. Jurnal Ilmiah Pendidikan Citra Bakti, 2 (1), 27-37.

$\mathrm{Na}$ Thalang, E. Education and Culture. In Na Thalang, E. (1991). Cultural Understanding. Bangkok : Amarint Printing Group.

Nuangchalerm, P. (2008). Reinforcement of Science Learning through Lokal Culture: A Delphi Study. [online]. http://files.eric.ed.gov/fulltext/ ED501192.pdf diunduh tanggal 18 Pebruari 2018.

Mayer, R. E. (2007). Multimedia Learning. New York: Cambridge University Press.

McGriff, S.J. (2000). Instructional Systems. New York: College of Education, Penn State University. [Online] melalui http://www.cdc.qc.ca/ actes_aqpc/2005/ellis_joanne_608.pdf, diakses 20 Maret 2015.

Salirawati. (2002). Strategi Siwa dalam Mengatasi Kesulitan Belajar. Makalah disampaikan pada kegiatan orientasi siswa baru SLTP N 15 Yogyakarta, tanggal 17 Juli 2002. Tidak diterbitkan.

Reigeluth, C.M. \& Carr-Cheliman, A.A. (2009). Theories for Different Outcomes of Instruction. Dalam C.M. Reigeluth, \& A.A. Carr-Cheliman (Eds.), Instructional-Design Theories and Models: Building a Common Knowledge Base, Vol. 3 (pp. 195-197), New York: Routledge 